\title{
Inversion of droplet aerosol analyzer data for long-term aerosol-cloud interaction measurements
}

\author{
M. I. A. Berghof ${ }^{1}$, G. P. Frank ${ }^{1}$, S. Sjogren ${ }^{1, *}$, and B. G. Martinsson ${ }^{1}$ \\ ${ }^{1}$ Department of Physics, Lund University, Lund, Sweden \\ * now at: University of Applied Sciences Northwestern Switzerland, Brugg-Windisch, Switzerland \\ Correspondence to: M. Berghof (maria.berghof@pixe.lth.se)
}

Received: 4 October 2013 - Published in Atmos. Meas. Tech. Discuss.: 29 November 2013

Revised: 21 February 2014 - Accepted: 25 February 2014 - Published: 4 April 2014

\begin{abstract}
The droplet aerosol analyzer (DAA) was developed to study the influence of aerosol properties on clouds. It measures the ambient particle size of individual droplets and interstitial particles, the size of the dry (residual) particles after the evaporation of water vapor and the number concentration of the dry (residual) particles. A method was developed for the evaluation of DAA data to obtain the three-parameter data set: ambient particle diameter, dry (residual) particle diameter and number concentration. First results from in-cloud measurements performed on the summit of Mt. Brocken in Germany are presented. Various aspects of the cloud-aerosol data set are presented, such as the number concentration of interstitial particles and cloud droplets, the dry residue particle size distribution, droplet size distributions, scavenging ratios due to cloud droplet formation and size-dependent solute concentrations. This data set makes it possible to study clouds and the influence of the aerosol population on clouds.
\end{abstract}

\section{Introduction}

Clouds affect the Earth's climate in a number of ways: for example, they regulate the hydrological cycle and redistribute energy via the transport of water vapor and latent heat in the atmosphere. Many factors influence the macrophysics and microphysics of clouds. The macrophysics of clouds are affected by large-scale meteorological conditions such as updraft velocity, turbulent mixing or atmospheric layering. Cloud droplets form by the condensation of water vapor on aerosol particles. As a consequence, the microphysical conditions are influenced by the macrophysics, the particle number concentration and size distribution, the chemical composition, and the mixing state of the atmospheric aerosol. The first (Twomey) indirect aerosol effect describes changes in cloud properties induced by changes in the properties of aerosol particles (Warner, 1968; Twomey, 1974; Albrecht, 1989; Liou and Ou, 1989; Lohmann and Feichter, 2005). It is still being debated as to whether changes in the microphysical properties of clouds also influence the amount of clouds and liquid water content. These changes are also associated with changes in precipitation efficiency and thus cloud lifetime (second indirect aerosol effect; Albrecht, 1989; Stevens and Feingold, 2009).

This work deals with an instrument, the droplet aerosol analyzer (DAA; Martinsson, 1996), developed for experimental studies of the interaction between aerosol and clouds. This instrument was especially developed to study the interaction between aerosol particles and cloud/fog droplets. The DAA measures the ambient size of individual droplets and interstitial particles, the size of the dry (residual) particles after the evaporation of water vapor and the number concentration. This gives a unique three-parameter data set (ambient particle diameter, dry (residual) particle diameter, and number concentration) for both cloud droplets and interstitial particles. The DAA can provide a direct relationship between cloud droplet size and the size of its dry residue. Other instrumentation for studying clouds, such as differential mobility particle spectrometers (DMPS), optical particle counters (OPC; Sorensen et al., 2011), the ground-based fog monitor (Spiegel et al., 2012) or the counterflow virtual impactor (CVI) that has a variable cut-off diameter for cloud droplets between 1 and $30 \mu \mathrm{m}$ (Anderson et al., 1993; Noone et al., 1988; Ogren et al., 1985; Schwarzenboeck and Heintzenberg, 
2000), cannot provide such a relationship, even when used in parallel.

Previous studies with the DAA include thorough intercomparisons (Cederfelt et al., 1997; Frank et al., 1998; Martinsson et al., 1999, 2000) with other cloud/aerosol instrumentation. Results from previous studies include relationships between particle and cloud number concentrations and cloud dynamics (Martinsson et al., 1997, 1999) as well as observations of validated cloud droplet number concentrations reaching up to $3000 \mathrm{~cm}^{-3}$ (Martinsson et al., 2000). Findings from previous DAA studies also include that fogs in polluted regions consisted of droplets that were not activated (Frank et al., 1998).

In order to improve the statistical description of the aerosol impact on cloud microstructure for different dynamical situations, long-term measurements are needed. The previous version of the DAA required daily service to ensure high-quality data. As a result, the instrument was only used in experiments spanning a month or less. Here we present parts of new developments of the DAA. The overall aims of the developments are twofold: to improve the time resolution in the measurements and to prepare the instrument for unattended long-term operation. The time resolution was improved by a factor of 2 by changing method of voltage change in the differential mobility analyzers (DMA) used in the DAA, increasing the number of DMAs from seven to eight where the new DMA provides more efficient coverage in terms of electrical mobility, and by changing the DMA aerosol to sheath air flow ratio. Methodology for long-term operation includes closedloop sheath air circulation in all DMAs, automated dryers for cloud droplets (Sjogren et al., 2013), automatic fill of liquid consumed by the particle detectors (condensation particle counter (CPC)), regular, remote access to operational parameters, and logging of a large number of parameters. These developments will be presented elsewhere. First results from measurements at Mt. Brocken (Germany) between June and October 2010 will be shown here. These improvements mean that large amounts of data can be produced to study the interaction between aerosols and clouds for different aerosols and for differences in cloud dynamics. The data produced need to be evaluated. The previous method was based on manual fit of the DAA spectra. Here we present an automated methodology to evaluate DAA data. The routine builds on the previous, manual, unpublished method.

\section{The DAA instrument}

A schematic of the DAA is shown in Fig. 1, and the instrument is described in more detail by Frank et al. (2014). It consists of an outdoor and an indoor part. Cloud droplets and interstitial particles are collected in the outdoor part through an inlet directed towards the wind. To achieve a well-defined charge state, the aerosol is first passed through a bipolar charger $(\mathrm{BiCh})$ and then a unipolar charger (UniCh), where

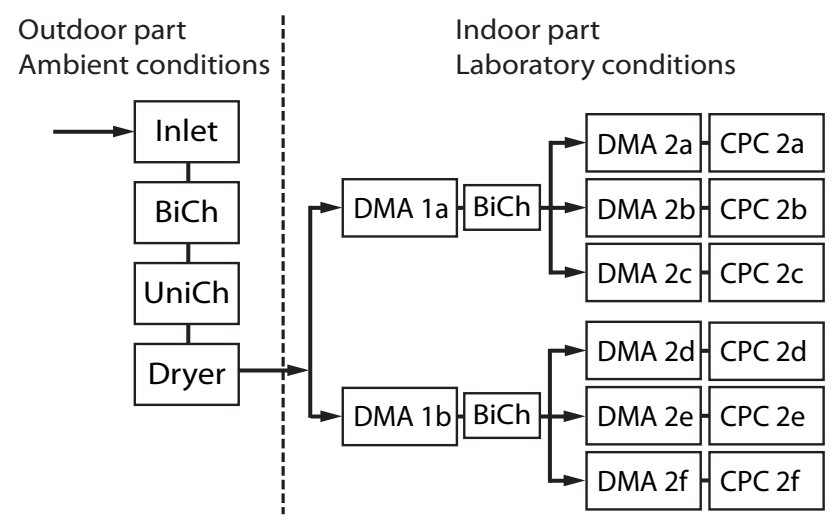

Fig. 1. The principle of the DAA. Droplets and particles are processed in several steps by aerosol charging mechanisms in bipolar (BiCh) and unipolar chargers (UniCh), diffusion drying (Dryer), electrostatic aerosol spectrometry (DMA), and counting in condensation particle counters (CPC) in order to obtain the desired relationships.

the droplets acquire a charge level dependent on their size while still at ambient conditions (Frank et al., 2004)). Water is removed in the dryer, described in Sjogren et al. (2013), and the dry aerosol then enters the indoor part.

At this stage the charge level of the particles is related to their ambient size. The particles are selected according to their electrical mobility in the first differential mobility analyzers (DMA 1a and 1b). The following combination of BiCh, DMA and CPC gives the electrical mobility of the singly charged droplet residuals for a given dry diameter. Once the dry particle diameter and the electric mobility of the residual particles are known, their charge state can be calculated, which is then related to the ambient particle diameter via the calibration of the unipolar charger.

During operation of the DAA, the voltage of the DMAs $2 \mathrm{a}-\mathrm{f}$ is fixed, while the voltage of DMA $1 \mathrm{a}$ and $1 \mathrm{~b}$ is varied over different charge levels from the unipolar charger. The mobility step between each of the DMAs 2a-f is set to 2 . The mobility step in DMA $1 \mathrm{a}$ and $1 \mathrm{~b}$ is set to $\sqrt{2}$ so as to coincide with the DMA 2 mobility of singly, doubly, quadruply, etc. charged particles from the unipolar charger. This allows for efficient detection of small particles carrying few elementary charges. From each DMA 1a and $1 \mathrm{~b}$ voltage a set of six measurements from DMA 2a to $f$ are obtained.

\section{DAA data evaluation}

An inversion technique was applied to the DAA raw data to obtain the three-parameter data set consisting of ambient particle diameter, dry (residual) particle diameter and number concentration. The basic variables were first calculated from the corrected raw data, resulting in the charge distribution caused by the unipolar charger (Fig. 1) for every dry particle 
diameter measured. Based on the calibration of the unipolar charger, a function can be derived to describe the relation between charge distribution and ambient particle size. In the second step of the data evaluation this function is used to extract the ambient particle diameter, $D_{\mathrm{d}}$, and concentration, $N_{\mathrm{UCh}}$, of particles and droplets entering the DAA corresponding to each charge distribution and thus to each dry (residual) particle diameter, $D_{\mathrm{p}}$. The DAA three-parameter data set thus consists of the ambient particle diameter, $D_{\mathrm{d}}$, the dry (residual) particle diameter, $D_{\mathrm{p}}$, and the number concentration, $N_{\mathrm{UCh}}$, in each dry particle interval measured.

\subsection{Raw data}

During one measurement run the voltage of DMA $1 \mathrm{a}$ and $1 \mathrm{~b}$ is stepped over different charge levels, while the voltage of DMA 2a-f is fixed. As the transport times in the instrument is known, it is possible to select steady-state data and to achieve a time resolution of $10 \mathrm{~min}$ for one complete measurement.

Two measurement runs are performed at two different voltages of DMA 2a-f. The first run is performed at voltages representing small diameters ( 59 to $545 \mathrm{~nm}$ ) and the second run is decreased by a factor of $\sqrt{2}$ in terms of electrical mobility, $Z_{\mathrm{p}}$, to increase the resolution in dry particle diameter ( 75 to $776 \mathrm{~nm}$ ). Both runs can be used independently, giving a time resolution of $10 \mathrm{~min}$ and a time resolution of $20 \mathrm{~min}$ with full size resolution.

The DAA raw data from each run consist of CPC raw counts, $N_{\text {counts }}$; the CPC counting time, $t_{\text {count }}$; the high voltage of DMA 1a and 1b and DMA 2a-f, $U$; the sheath air flow, $Q_{\text {sh }}$; and the aerosol flow, $Q_{\text {ae }}$, for each DMA; as well as atmospheric pressure, $p$, and aerosol temperature $T_{\mathrm{ae}}$. The dry particle diameter, $D_{\mathrm{p}}$; electrical mobility, $Z_{\mathrm{p}}$; electrical charge level, $q_{\mathrm{DAA}}$; and the raw number concentration, $N_{\text {raw }}$, can be calculated from this data set.

\subsection{Data correction}

The DAA raw concentration is corrected for losses that occur after the second bipolar charger (losses in DMA 2a-f). Corrections are also made for particle losses in DMA $1 \mathrm{a}$ and $1 \mathrm{~b}$ that occur upstream of the bipolar charger. The loss-corrected concentration data are then corrected for multiple charging in the second bipolar charger. The results are further corrected after the inversion for minor losses in the dryer (Sjogren et al., 2013) and for deviations from isokinetic sampling of the inlet (Sect. 3.3).

\subsubsection{DMA correction}

A perfect DMA can be described by an ideal, symmetric transfer function, which is triangular. Imperfections in the DMA may result in broadening of the transfer function and losses of particles (Martinsson et al., 2001). Further losses and broadening due to Brownian diffusion can cause the transfer function to be dependent on particle size
(Stolzenburg, 1988). Two parameters are used to characterize the imperfections of the DMAs. A broadening factor, $\mu(\leq 1)$, describes the width of the transfer function leading to a broader individual transfer function while conserving its area. Particle loss is described by a loss factor, $\lambda(\leq 1)$, leading to a decrease in area while conserving its width. Both parameters are specific to each DMA and were determined experimentally for $230 \mathrm{~nm}$ particles, as described in Martinsson et al. (2001). The size dependence of both parameters was estimated as described in Karlsson and Martinsson (2003). The resulting parameters were averaged for each DMA over both DAA runs, leading to an error of less than $0.5 \%$ due to the size dependence of Brownian diffusion. The estimates for the eight DMAs are in the range $\mu=0.87$ to 1.00 and $\lambda=0.81$ to 1.00. Both DMA loss and broadening are accounted for in each charge distribution before the bipolar charge correction.

Another feature of the instrument is the size range covered by each of the DMA 2a-f. During a run the voltage of DMA 2a-f is kept constant and the mobility step between each of the DMAs 2a-f is set to 2. In order to quantify the mobility distribution, each DMA measurement must be converted to represent the DMA stepping factor used as described by Cederfelt et al. (1997).

\subsubsection{Bipolar charger correction}

The ambient particles and droplets entering the DAA are charged, then dried and selected according to charge level in DMA 1a and 1b. Before entering the second series of DMAs, the particles selected by DMA 1a and $1 \mathrm{~b}$ are multiply charged in a bipolar charger.

In order to correct for multiple charging, it was assumed that the influence of multiply charged particles larger than the largest particle size measured in each run could be neglected. This is approximately valid for size distributions showing a rapid decrease in number concentration with increasing size, which is usually the case for atmospheric aerosol at the maximum sizes in the two different DMA runs (593 and $751 \mathrm{~nm}$ ). For gradients of a factor of 10 between the largest size and the size corresponding to a factor of 2 increase in electrical mobility, the error for the latter size will be less than $1 \%$. Due to the strong gradient, this error will not propagate to smaller sizes. Doubly and quadruply charged particles with a dry particle diameter measured by a certain DMA 2a-f will have a higher mobility. These will be detected by the DMA $2 \mathrm{a}-\mathrm{f}$ measuring the closest and second-closest smaller dry particle diameter. Their fractions were calculated based on the charge distribution described in Wiedensohler (1988).

To be able to correct for triply charged particles, a linear relation was assumed between the concentration of triply charged particles and the concentration of doubly and quadruply charged particles. The fraction of triply charged particles, $f\left(D_{\mathrm{P}},-3\right)$, can thus be included in the fraction of doubly, $f\left(D_{\mathrm{P}},-2\right)$, and quadruply, $f\left(D_{\mathrm{P}},-4\right)$, charged particles: 
$f_{D_{\mathrm{P}},-2}^{*}=f_{D_{\mathrm{P}},-2}+\frac{1}{2} f_{D_{\mathrm{P}},-3}$,

$f_{D_{\mathrm{P}},-4}^{*}=f_{D_{\mathrm{P}},-4}+\frac{1}{2} f_{D_{\mathrm{P}},-3}$.

The uncertainty of this approximation is dependent on particle size and the width of size modes. The strongest effects can be expected when the triply charged particle is at the peak of a mode. An aerosol with narrow aerosol modes was found in Hoppel et al. (1996). The number concentration of triply charged particles close to the peak at $180 \mathrm{~nm}$ diameter will be underestimated by $15 \%$. The effect on the only important result, i.e., the number of singly charged particles, would be an overestimation by $1.4 \%$. Due to the dominance of single charge for still smaller particles, the error will not propagate. For distributions with modes more narrow than in Hoppel et al. (1996) (Fig. 1), the error due to the approximation will be larger. The charge distribution measured in each of the DMA 2a-f is thus corrected by subtracting the determined amount of doubly and quadruply charged particles from the other DMA 2a-f channels.

Finally, the concentration is corrected to standard laboratory pressure $(1013.25 \mathrm{hPa})$ and temperature $(293.15 \mathrm{~K})$ giving the charge distribution measured by the DAA, $N^{\mathrm{DAA}}\left(q_{\mathrm{DAA}}\right)$.

\subsection{DAA inversion algorithm}

After applying the above-described corrections, we obtained the corrected charge distribution of the ambient aerosol as measured by the DAA. Figure 2 shows the DAA data obtained during one run for each of the DMA 2a-f with its corresponding dry particle diameter, $D_{\mathrm{P}}$. For small charge levels (i.e., small ambient particles), singly and doubly charged particles can be observed, whereas particles with two consecutive charge levels cannot be resolved higher up in the spectrum. In the next step, a function is fitted to the data, as shown in Fig. 2. The function fitted is the resulting charge distribution of droplets of a certain ambient particle diameter $D_{\mathrm{d}}$ passing through the DAA system, using the ambient particle diameter, $D_{\mathrm{d}}$, and the number concentration of particles entering the unipolar charger, $N_{\mathrm{UCh}}$, as fitting variables. The following section describes how this function is obtained by first calculating the charge distribution downstream of the unipolar charger, and then the charge distribution downstream of DMA 1a and 1b and DMA 2a-f.

\subsubsection{Unipolar charger}

When the aerosol enters the DAA it first passes through a bipolar charger to achieve a well-defined charge state. By passing the unipolar charging unit the aerosol acquires positive charges depending on their particle diameter. The resulting charge distribution thus depends on the ambient size of the particles entering the DAA. The relation between the

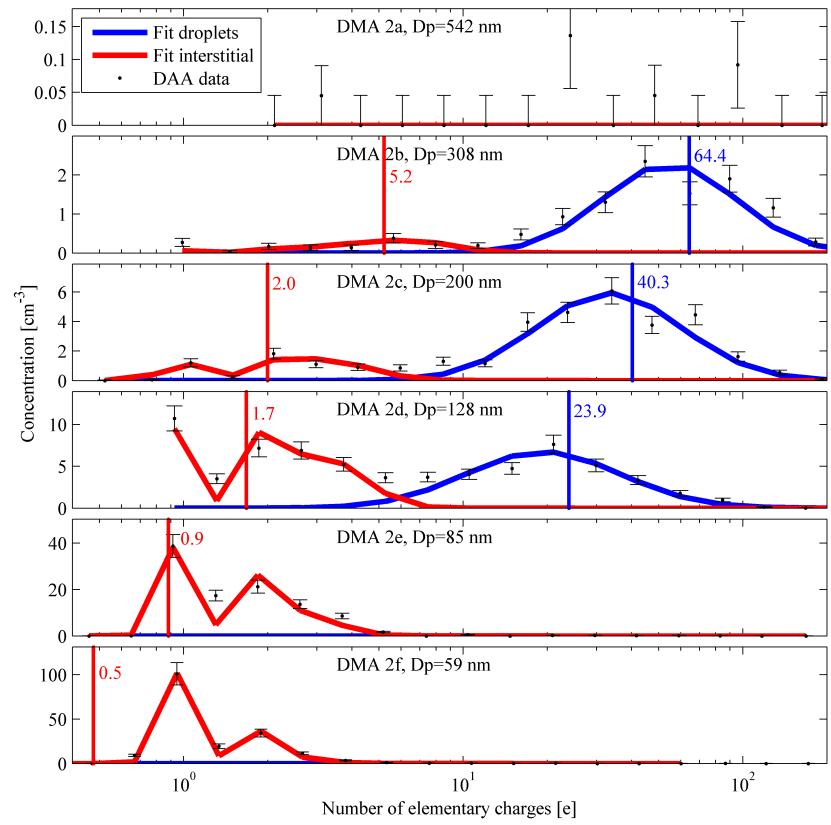

Fig. 2. Example of results obtained from data collected at Mt. Brocken, one run from 31 August 2010, 00:53-01:03 UTC. The panels show charge distribution data from the DMA $2 \mathrm{a}-\mathrm{f}$, including the standard error for Poisson counting of the raw counts. In this example, one or two fits were performed for each DMA 2a$\mathrm{f}$, which can be classified as interstitial particles and droplets. In the top panel, showing the results from DMA 2a for the largest dry particle diameter measured in this run, and in the two lowest panels, showing the results for the two smallest dry particle diameters measures (DMA 2e and 2f), there were insufficient particles and droplets to allow for a fit. Note the varying scale on the $y$ axes.

arithmetic mean charge level and the mean ambient particle diameter in micrometers was calibrated in the size range 0.12 to $17 \mu \mathrm{m}$ by Frank et al. (2004), and has been used here:

$D_{\mathrm{d}}\left(q_{\mathrm{a}}\right)=-2.394+\left(3.103+0.377 \times q_{\mathrm{a}}\right)^{0.771}$.

Only particles becoming positively charged by the unipolar charger will be detected in the system. To determine the ambient particle size and concentration, the fraction of singly and doubly charged particles must be detectable. This may not be the case for ambient particles with small diameters at low concentrations, since the fraction of detected doubly charged particles may be too small. This leads to an error when determining the ambient particle size. For ambient particles with a size of $D_{\mathrm{P}}=50 \mathrm{~nm}$, the error in ambient size is $10 \%$ for a concentration of $\mathrm{d} N / \mathrm{d} \log D_{\mathrm{p}}=12.5 \mathrm{~cm}^{-3}$.

Large particles can be lost in the DAA inlet; thus the upper limit was set to $25 \mu \mathrm{m}$. The calibration range is therefore somewhat smaller than the measurement range. The calibration range was extrapolated by Frank et al. (2004) based on the charging model presented by Lawless (1996). 
An $\alpha$ source, Cm-244, used to charge particles passing through the unipolar charger. Since the half-life of this source is 18.1 years, the calibration performed by Frank et al. (2004) may have changed, since radioactive decay would have resulted in a decrease in the number of charges for a certain droplet size. Therefore, the ambient particle diameter used here may be slightly underestimated. However, this will not affect the main subject of this paper.

\subsubsection{Charge distribution downstream of the unipolar charger}

The shape of the charge distribution downstream of the unipolar charger depends on the ambient particle size, $D_{\mathrm{d}}$, of the entering particles. Calibrations show that the charge distribution downstream of the unipolar charger for particles smaller than $0.61 \mu \mathrm{m}$ follows a normal distribution, whereas for particles larger than $3.15 \mu \mathrm{m}$ it follows a log-normal distribution. Between these limits a linear combination of both distributions was used.

Ambient particles and droplets smaller than $0.61 \mu \mathrm{m}$ acquire an arithmetic mean charge below $q_{a}=2.82$. Their resulting charge distribution downstream of the unipolar charger follows a normal distribution,

$$
\begin{aligned}
& \frac{\mathrm{d} N_{[<0.61 \mu \mathrm{m}]}^{\text {Charger }}\left(\boldsymbol{q}_{\mathrm{i}}\right)}{\mathrm{d} q_{\mathrm{i}}}= \\
& \frac{N_{\mathrm{UCh}}}{\sqrt{2 \pi} \sigma_{\mathrm{a}}} \exp \left(-\frac{1}{2}\left(\frac{\boldsymbol{q}_{\mathrm{i}}-q_{\mathrm{a}}}{\sigma_{\mathrm{a}}}\right)^{2}\right),
\end{aligned}
$$

for integer charge bins $\boldsymbol{q}_{\mathrm{i}}$ and an arithmetic mean charge of $q_{\mathrm{a}}$ and standard deviation $\sigma_{\mathrm{a}}$

$q_{\mathrm{a}}=\frac{\left(D_{\mathrm{d}}[\mu \mathrm{m}]+2.394\right)^{\frac{1}{0.771}}-3.103}{0.377}$

$\sigma_{\mathrm{a}}=\sqrt{0.28+1.51 q_{\mathrm{a}}}$.

Ambient particles and droplets larger than $3.15 \mu \mathrm{m}$ acquire an arithmetic mean charge greater than $q_{\mathrm{a}}=16.23$. Their resulting charge distribution downstream of the unipolar charger follows a log-normal distribution (Frank et al., 2004),

$\frac{\mathrm{d} N_{[>3.15 \mu \mathrm{m}]}^{\text {Charger }}\left(q_{\mathrm{i}}\right)}{\mathrm{d} \log q_{\mathrm{i}}}=\frac{N_{\mathrm{UCh}}}{\sqrt{2 \pi} \log \left(\sigma_{\mathrm{g}}\right)} \exp \left(-\frac{\log ^{2}\left(\frac{\boldsymbol{q}_{\mathrm{i}}}{q_{g}}\right)}{2 \log ^{2}\left(\sigma_{g}\right)}\right)$,

for integer charge bins $\boldsymbol{q}_{\mathrm{i}}$ and a geometric mean charge of $q_{\mathrm{g}}$ and standard deviation $\sigma_{\mathrm{g}}$ :

$q_{\mathrm{g}}=\frac{q_{\mathrm{a}}}{\exp \left(\frac{\log ^{2}\left(\sigma_{\mathrm{g}}\right)}{2}\right)}$

$\sigma_{\mathrm{g}}=1.99-0.027 D_{\mathrm{d}}$

with $D_{\mathrm{d}}$ in $\mu \mathrm{m}$.
In the size range $0.61-3.15 \mu \mathrm{m}$, ambient particles and droplets acquire an arithmetic mean charge of $q_{\mathrm{a}}=2.82$ to 16.23. Here, a combination of normal and log-normal distributions was used,

$N_{[0.61-3.15 \mu \mathrm{m}]}^{\text {Charger }}\left(q_{\mathrm{i}}\right)=$

$\left(1-\boldsymbol{\xi}\left(q_{\mathrm{i}}\right)\right) \times \mathrm{d} q_{\mathrm{i}} \times\left(\frac{N_{\mathrm{UCh}}}{\sqrt{2 \pi} \sigma_{\mathrm{a}}} \exp \left(-\frac{1}{2}\left(\frac{\boldsymbol{q}_{\mathrm{i}}-q_{\mathrm{a}}}{\sigma_{\mathrm{a}}}\right)^{2}\right)\right)$

$+\boldsymbol{\xi}\left(q_{\mathrm{i}}\right) \times \operatorname{dlog} q_{\mathrm{i}} \times\left(\frac{N_{\mathrm{UCh}}}{\sqrt{2 \pi} \log \left(\sigma_{\mathrm{g}}\right)} \exp \left(-\frac{\log ^{2}\left(\frac{\boldsymbol{q}_{\mathrm{i}}}{q_{\mathrm{g}}}\right)}{2 \log ^{2}\left(\sigma_{\mathrm{g}}\right)}\right)\right)$,

for integer charge bins $\boldsymbol{q}_{\mathrm{i}}$ and the linearly increasing factor $\xi\left(q_{\mathrm{i}}\right)$ :

$\xi\left(q_{\mathrm{i}}\right)=$

$\left\{\begin{array}{ll}0, & \boldsymbol{q}_{\mathrm{i}} \leq 2.82 \\ \left(\boldsymbol{q}_{\mathrm{i}}-2.82\right) /(16.23-2.82), & 2.82<\boldsymbol{q}_{\mathrm{i}}<16.23 \\ 1, & \boldsymbol{q}_{\mathrm{i}} \geq 16.23\end{array}\right.$.

The resulting charge distribution downstream of the unipolar charger is used to calculate the charge distribution downstream of both series of DMAs, as described below.

\subsubsection{Charge distribution downstream of the DMAs}

The charged droplets downstream of the unipolar charger are dried and passed through DMA $1 \mathrm{a}$ and $1 \mathrm{~b}$ and one of the second series of DMAs (2a-f). The calculated charge distribution downstream of the DMAs, $f_{\text {fit }}$, is then compared with the measured DAA charge distribution.

It is important to know the individual transfer functions of each of the DMAs in order to estimate the charge distribution downstream of the DMAs. Due to the width of the DMA transfer function when measuring a certain charge, $q_{\text {set }}$, particles within a certain charge range $\left[q_{\min }, q_{\max }\right]$ will be selected. The fraction of particles with charges $\boldsymbol{q}_{\mathrm{i}}=1,2, \ldots, n$ measured in a certain charge bin, $\boldsymbol{q}_{\mathrm{DAA}}$, of the DAA can be calculated by convolution of the transfer function of DMA $1 \mathrm{a}$ or $1 \mathrm{~b}$ and the corresponding of the DMA 2a-f. These fractions can be expressed in the transmission matrix, T. For an ideal DMA with a flow ratio of $\frac{Q_{\mathrm{ae}}}{Q_{\mathrm{sh}}}=\frac{1}{4}$ it can be derived as (here, only part of the matrix is given):

$\boldsymbol{q}_{\mathrm{DAA}}=(\sqrt{2}, 2,2 \sqrt{2}, 4)$,
$\boldsymbol{q}_{\mathrm{i}}=(1,2,3,4,5,6,7)$,

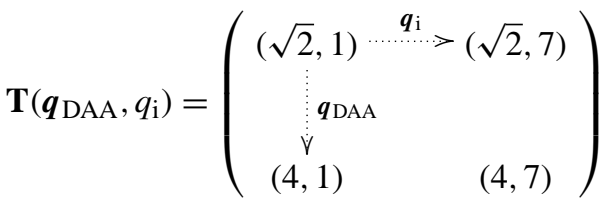

$=\left(\begin{array}{ccccccc}0.036 & 0.051 & 0 & 0 & 0 & 0 & 0 \\ 0 & 0.667 & 0.014 & 0 & 0 & 0 & 0 \\ 0 & 0.036 & 0.636 & 0.051 & 0 & 0 & 0 \\ 0 & 0 & 0.094 & 0.667 & 0.256 & 0.014 & 0\end{array}\right)$. 
This example shows that around $66.7 \%$ of the particles with a charge of $q_{\mathrm{i}}=2$ will appear in the DMA channel corresponding to charge $q_{\mathrm{DAA}}=2,5.1 \%$ will appear in the DMA channel corresponding to charge $q_{\mathrm{DAA}}=\sqrt{2}$, and $3.6 \%$ in the DMA channel corresponding to charge $q_{\mathrm{DAA}}=2 \sqrt{2}$.

The charge distribution downstream of the DMAs is the sum of the product of each row of the transmission matrix $\mathbf{T}$ and the charge distribution downstream of the unipolar charger $N^{\text {Charger }}\left(q_{i}\right)$,

$$
\begin{aligned}
& \boldsymbol{f}_{\text {fit }}\left(q_{\text {DAA }}\right) \\
& =\sum_{i}\left(\mathbf{T}\left(\boldsymbol{q}_{\text {DAA }}, \mathbf{q}_{\mathrm{i}}\right) \times \boldsymbol{N}^{\text {Charger }}\left(\boldsymbol{q}_{\mathrm{i}}\right)\right) .
\end{aligned}
$$

The function $\boldsymbol{f}_{\text {fit }}$ is the calculated charge distribution, assuming that $N_{\mathrm{UCh}}$ particles and droplets of ambient particle size $D_{\mathrm{d}}$ enter the unipolar charger. Values of the coefficients $N_{\mathrm{UCh}}$ and $D_{\mathrm{d}}$ can be found by nonlinear least-squares curve fitting of the fit function $\boldsymbol{f}_{\text {fit }}$ to the measured DAA data $N^{\text {DAA }}\left(q_{\text {DAA }}\right)$. It is possible to use more than one size for the ambient particles and droplets.

Having determined the values for the variables $N_{\mathrm{UCh}}$ and $D_{\mathrm{d}}$ from the fit, it is possible to directly relate ambient particle diameter, dry (residual) particle diameter and number concentration.

\subsubsection{Inlet correction}

$N_{\mathrm{UCh}}$ is the concentration of particles entering the unipolar charger. In the last step of the data evaluation, losses in the DAA inlet must be accounted for. A wind vane, which consists of an exchangeable cone followed by a $90^{\circ}$ bend connected to the unipolar charger unit, directs the DAA inlet towards the wind. Three inlet cones are available, designed for isokinetic sampling at wind speeds of 2,5 and $10 \mathrm{~m} \mathrm{~s}^{-1}$. Depending on the actual wind speed, certain ambient particle diameters may be over- or underrepresented in the sampled aerosol. To obtain the concentration, $N$, of particles entering the DAA inlet, the calculated concentration of particles entering the unipolar charger obtained from the fit, $N_{\mathrm{UCh}}$, must be corrected. The correction depends on the isokinetic sampling speed of the inlet, the actual wind speed and the ambient particle diameter of the aerosol particles, $D_{\mathrm{d}}$, and was performed as described by Belyaev and Levin (1974).

\subsection{Uncertainties}

The uncertainties given here are based on laboratory tests. Intercomparisons with other aerosol/cloud sizing instrumentation, which were undertaken with the previous DAA version (Cederfelt et al., 1997; Frank et al., 1998; Martinsson et al., 1999, 2000), have not yet been undertaken with the new version. The DAA measures the number concentration, dry particle diameter and ambient particle diameter. The uncertainty in dry particle diameter is estimated to be $6 \%$, and is due to the uncertainties in the DMA high voltage (estimated to be $2 \%$ ), the sheath air flow (estimated to be $2 \%$ ) and the geometrical dimensions of the DMAs (inner and outer radius and electrode length) (estimated to be $5 \%$ ). The uncertainty in ambient particle diameter is estimated to be $12 \%$, due to uncertainties in the DMA high voltage (estimated to be $2 \%$ ), the sheath air flow (estimated to be $2 \%$ ), the geometrical dimensions of the DMAs (estimated to be $5 \%$ ) and the calibration curve used for the unipolar charger (estimated to be $10 \%$ ). Additional uncertainty, at present not quantified, will arise from the decay of the radioactive source in the unipolar charger. The estimated uncertainty in the number concentration $\mathrm{d} N / \mathrm{d} \log D_{\mathrm{p}}$ for each dry particle diameter obtained from the fitted function is below $13 \%$ for ambient concentrations above $\mathrm{d} N / \mathrm{d} \log D_{\mathrm{p}}=50 \mathrm{~cm}^{-3}$. This is due to the uncertainties in the standard error for Poisson counting of the raw counts, the uncertainty in aerosol flow (regulated by a proportional-integral-derivative controller (PID), estimated to be $5 \%$ ), the correction for the mobility range covered (estimated to be $10 \%$ ), and the bipolar charge correction (estimated to be $5 \%$ ).

\section{Results}

After fitting the ambient size distribution for each of the six dry particle diameters measured, it is possible to calculate the ambient particle and dry particle size distributions and several other parameters, as described in this section.

\subsection{The capability of the DAA}

In 2010, the DAA was placed at the summit of Mt. Brocken in the Harz region of central Germany to perform incloud measurements. An event with stable cloud conditions (31 August 2010, 23:30 UTC, to 1 September, 01:30 UTC) was selected to demonstrate the capability of the DAA. The DAA directly relates ambient particle diameter, dry (residual) particle diameter and the number concentration, as, for example, shown in Fig. 3a. Interstitial particles (red) and droplets (blue) can be identified. The cloud droplets were between 6 and $13 \mu \mathrm{m}$ in diameter, and formed on particles in the size range 86 to $546 \mathrm{~nm}$. The interstitial aerosol formed on dry (residual) particles in the size range from 50 to $300 \mathrm{~nm}$, and had ambient particle diameters from 0.13 to $1.1 \mu \mathrm{m}$. The three black lines in the $x-y$ plane indicate the critical diameter of activation according to Köhler's theory for different volume fractions of ammonium sulfate in the particles, $D_{\mathrm{V}(\mathrm{AS})}^{*}$. For large dry particle size, those lines can intersect the drop mode; this indicates that some of the cloud droplets might not have been activated according to Köhler's theory. Although the droplets formed on large dry particles might not be activated according to Köhler's theory, they would be larger than the activated droplets formed on smaller nuclei, and should be regarded as cloud droplets. Both ambient and 


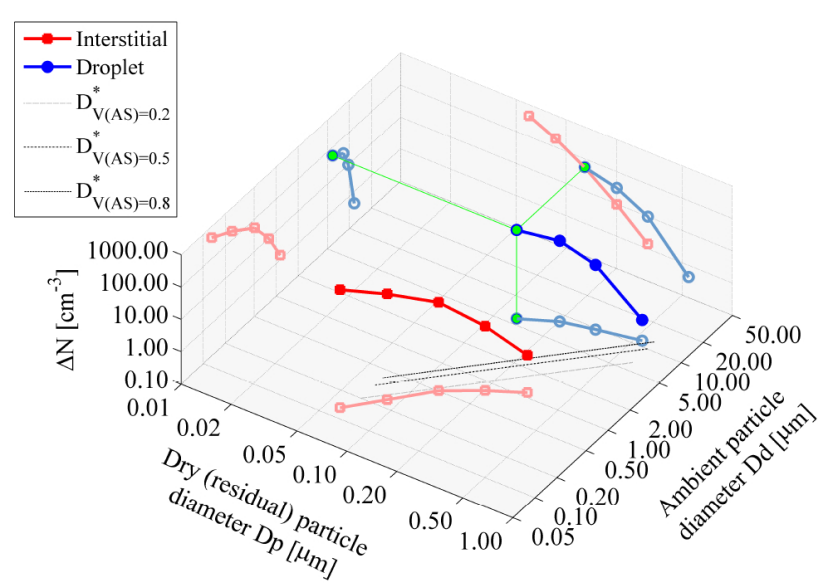

(a)

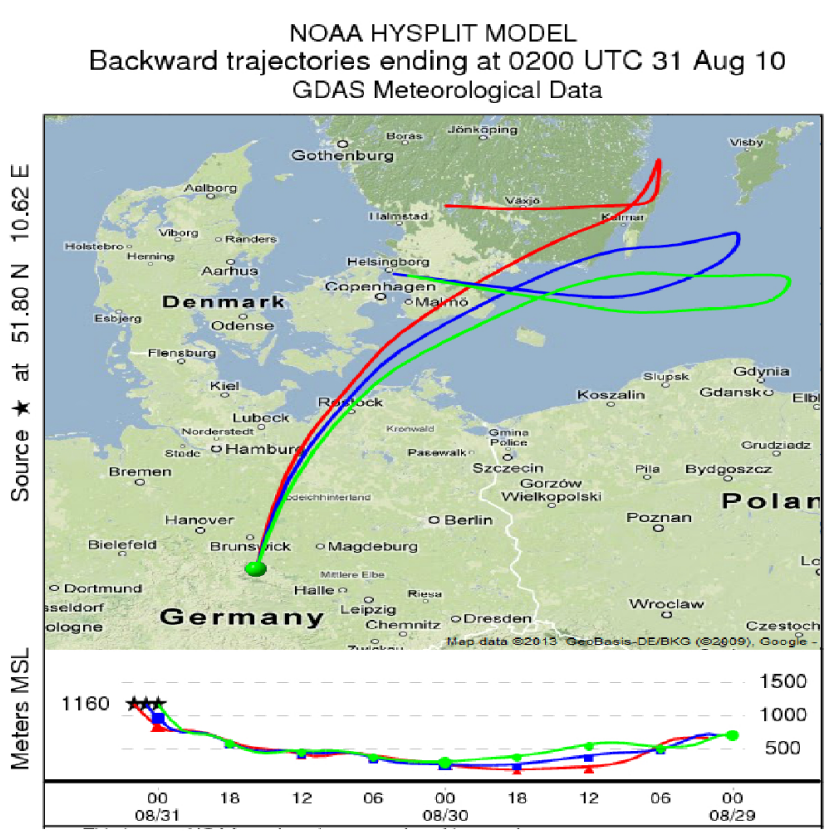

(b)

Fig. 3. (a) Concentration in each measured size interval $\Delta N$ of droplets and residual particles as a function of ambient particle and dry particle diameter on 31 August 2010, 23:51 UTC. The three black lines in the $D_{\mathrm{P}}-D_{\mathrm{d}}$ plane indicate the critical diameter of activation according to Köhler's theory for different volume fractions of ammonium sulfate in the particles, $D_{\mathrm{V}(\mathrm{AS})}^{*}$. The projections in paler colors show the distribution of ambient particles (left, $D_{\mathrm{d}}-\Delta N$ plane), the distribution of dry (residual) particles (right, $D_{\mathrm{P}}-\Delta N$ plane) and ambient particle diameter $D_{\mathrm{d}}$ as a function of dry (residual) particle diameter $D_{\mathrm{P}}$ (bottom, $D_{\mathrm{P}}-D_{\mathrm{d}}$ plane). (b) The $48 \mathrm{~h}$ back trajectories arriving at Mt. Brocken at 23:00 UTC, 30 August 2010 (green) and 01:00 UTC (blue) and 02:00 UTC (red), 31 August 2010, derived with the HYSPLIT model are shown. The HYSPLIT trajectories arrive at $1161 \mathrm{~m}$ a.s.l., representing $20 \mathrm{~m}$ above the station at the summit of Mt. Brocken (Draxler and Rolph, 2013) dry (residual) size distributions can be derived by projecting the concentration onto the corresponding axis and dividing by $\operatorname{d} \log D_{\mathrm{P}}$ or $\operatorname{d} \log D_{\mathrm{d}}$ as explained below.

For the selected event, $48 \mathrm{~h}$ back trajectories from Mt. Brocken were derived with the HYSPLIT model (Draxler and Rolph, 2013), as shown in Fig. 3. They show that the air arrived via southern Sweden and the Baltic Sea northeast of Mt. Brocken, a region with an annual fine-matter average $\left(\mathrm{PM}_{2.5}\right)$ of less than $10 \mu \mathrm{g} \mathrm{m}^{-3}$ according to the European Environment Agency (2012). The air approached Mt. Brocken via northeastern Germany from the north $\left(\mathrm{PM}_{2.5}\right.$ of 10 to $20 \mu \mathrm{g} \mathrm{m}^{-3}$ ) with an average wind speed of $10 \mathrm{~m} \mathrm{~s}^{-1}$ and ambient temperature of $5^{\circ} \mathrm{C}$, measured at the measurement station on summit of Mt. Brocken.

The total number concentration of dry (residual) particles from cloud droplets and interstitial particles in the dry particle size range 49 to $563 \mathrm{~nm}$ during the event was stable at $515 \pm 50 \mathrm{~cm}^{-3}$ with $416 \pm 47 \mathrm{~cm}^{-3}$ interstitial particles and $100 \pm 9 \mathrm{~cm}^{-3}$ droplets, as can be seen in Fig. 4a.

During the event, droplets formed on particles that were $85 \mathrm{~nm}$ and larger, i.e., mainly on accumulation mode particles, the highest drop concentration being observed for $168 \mathrm{~nm}$ particles (denoted by the blue circles in Fig. 4). Since accumulation mode particles have a long lifetime if not removed by rainout or washout, their source region may be southern Sweden as well as the Baltic Sea and northern Germany.

The scavenging ratio (number of cloud droplets divided by the total number concentration) can be obtained either from pre-cloud size distribution combined with cloud interstitial measurements or from size distributions of cloud droplet and interstitial particles dry residuals. The former method suffers from low precision due to problems of sampling the same air mass, whereas the latter does not exactly describe the size distribution of the aerosol entering the cloud due to the possible effect of chemical processing in clouds. Figure 4 shows the scavenging ratio of the latter kind. A steep rise for particles up to $150 \mathrm{~nm}$ can be seen, while for larger particles the increase is slower. A double sigmoid was fitted to the data (black line) and the diameter of $50 \%$ activation of $130 \mathrm{~nm}$ is indicated (green vertical line). The scavenging ratio is similar to that in previous studies by Svenningsson et al. (1997), Martinsson et al. (1999) and Mertes et al. (2005), the steep rise indicating a higher degree of internally mixed particles and more hygroscopic particles. The slower increase for particles larger than $150 \mathrm{~nm}$ may be due to more externally mixed particles with a fraction of less hygroscopic particles that gradually become activated, although the larger size would, on the other hand, favor droplet formation for particles of similar composition.

The size of the ambient cloud interstitial aerosol particles in the cloud in relation to their dry particle size shows a steady increase for the smallest residue sizes, as shown in Fig. 5. This increase would continue throughout the measured dry particle size range for particles of similar 


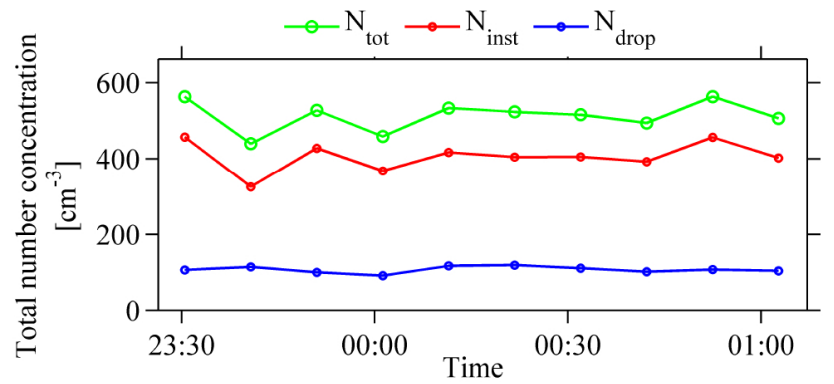

(a)

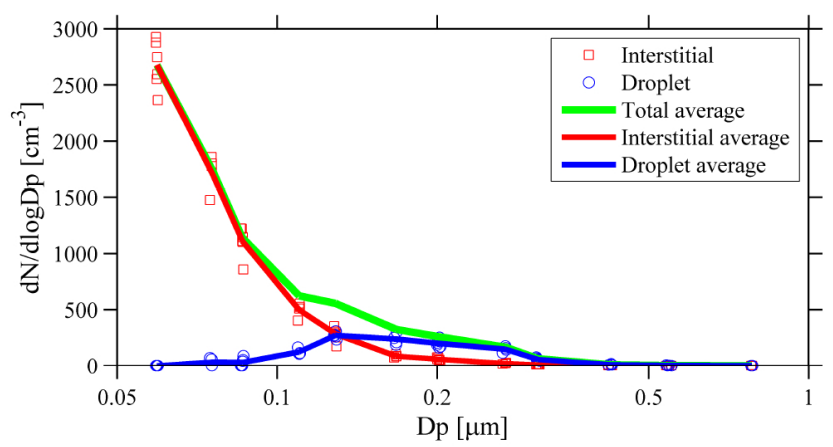

(b)

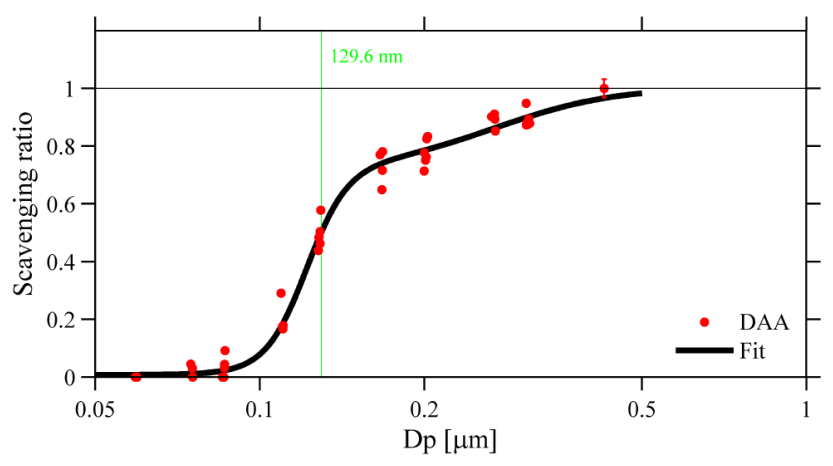

(c)

Fig. 4. (a) The total, interstitial and droplet number concentrations during the event, in the size range 49 to $563 \mathrm{~nm}$. (b) Dry (residual) particle size distribution, $\mathrm{d} N / \mathrm{d} \log D_{\mathrm{p}}$, of interstitial particles and droplets including averages (lines). (c) DAA scavenging ratio during the cloud event (red dots) with error bars indicating the estimated standard deviation in DAA counts during the event (smaller than the marker size for almost all data points), and a log-normal double-sigmoid fit (black line). The diameter for $50 \%$ activation is $0.13 \mu \mathrm{m}$, indicated by the green line.

composition, because the interstitial aerosol can be expected to be at equilibrium with the surrounding air. As can be seen in Fig. 5, the rate of increase in ambient particle size with dry particle size decreases in the region around $D_{50}(130 \mathrm{~nm})$. This strongly indicates preferential cloud droplet nucleation scavenging of more hygroscopic particles, whereas the less hygroscopic particles remain as interstitial particles.
The settings of the DMA $2 \mathrm{a}-\mathrm{f}$ of the DAA are based on dry particle size. Therefore, dry distributions can be obtained directly. To obtain the ambient particle size distribution, a function is fitted to the ambient particle diameter, $D_{\mathrm{d}}$, as a function of dry (residual) particle diameter, $D_{\mathrm{P}}$, for each measurement obtained. By differentiating d $\log D_{\mathrm{P}}$ with respect to $\mathrm{d} \log D_{\mathrm{d}}$, the function $\frac{\operatorname{d} \log D_{\mathrm{P}}}{\operatorname{d} \log D_{\mathrm{d}}}$ is obtained, and the ambient particle size distribution is calculated from the dry (residual) particle size distribution as follows (Frank et al., 1998):

$\frac{\mathrm{d} N}{\mathrm{~d} \log D_{\mathrm{d}}}=\frac{\mathrm{d} N}{\mathrm{~d} \log D_{\mathrm{P}}} \frac{\mathrm{d} \log D_{\mathrm{P}}}{\mathrm{d} \log D_{\mathrm{d}}}$.

The ambient size distribution obtained (Fig. 5b) is another unique feature of the DAA and shows that interstitial particles below $1 \mu \mathrm{m}$ are separated from the drop mode by a gap around the ambient particle diameter of $2 \mu \mathrm{m}$ with a mean ambient particle diameter of $6 \mu \mathrm{m}$.

Another application of the DAA data products is the estimation of the solute concentration as a function of cloud droplet size. This can be achieved from the dry particle volume; measurements of its hygroscopic properties, for example, using a hygroscopic tandem differential mobility analyzer (H-TDMA); and the volume of the cloud droplet. Since we did not have access to H-TDMA data, we assumed approximately constant hygroscopic properties. This study concerns European continental air masses. For such air masses the volume fraction of soluble matter in dry particles of the size range between 0.1 and $0.5 \mu \mathrm{m}$ was approximated to 0.5 ammonium sulfate and 0.5 insoluble material in approximate accordance with Kandler and Schütz (2007). In Fig. 5c it can be seen that the solute concentration depends strongly on the size of the dry (residual) particles. Particle size dependence of the dry particle soluble fraction usually varies by much less than \pm 0.25 (Kandler and Schütz, 2007), i.e., much smaller than the size dependence in the solute concentration, which was based on assumption of a size-independent particle soluble fraction. Limitations in vapor transport by diffusion prevent droplets formed on large particles from increasing in volume at the same relative rate as droplets formed on smaller particles.

\section{Conclusions}

The DAA was developed specifically for studying the interaction between aerosol particles and cloud/fog droplets. It collects droplets and interstitial particles under ambient conditions and can be used to determine the ambient particle size of individual droplets and the number and sizes of the dry (residual) particles after evaporation of the water. This gives a unique three-parameter data set (ambient particle diameter, dry (residual) particle diameter and number concentration).

The DAA inversion approach presented here employs basic corrections to the DAA raw data and different steps to convert the ambient particle charge distributions for certain 


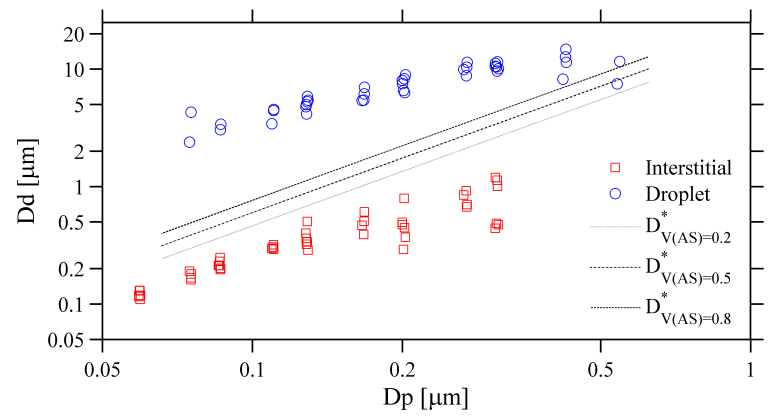

(a)

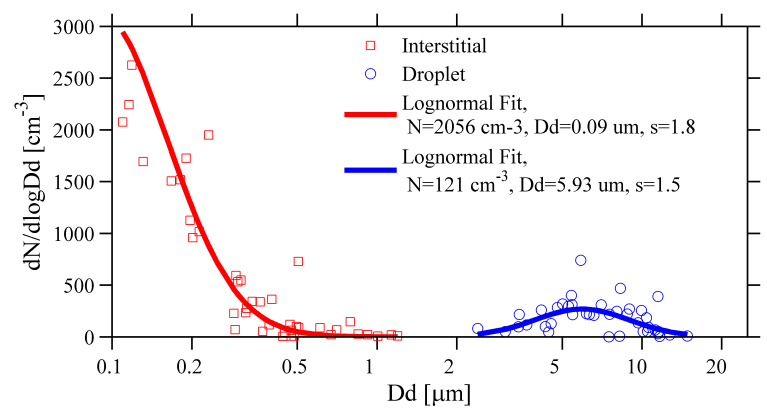

(b)

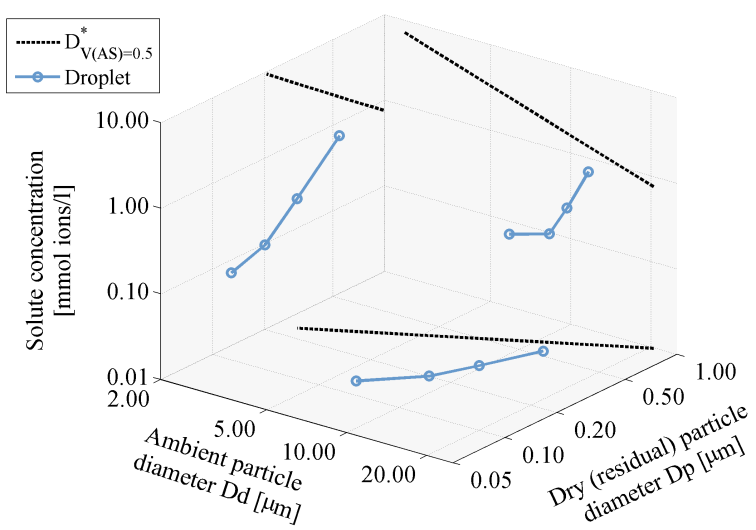

(c)

Fig. 5. (a) Ambient particle diameter, $D_{\mathrm{d}}$, as a function of dry (residual) diameter, $D_{\mathrm{P}}$, during the event. The three black lines show the critical diameter of activation $D_{\mathrm{V}(\mathrm{AS})}^{*}$ for different volume fractions of ammonium sulfate in the particles. (b) Ambient particle size distribution, $\mathrm{d} N / \mathrm{d} \log D_{\mathrm{d}}$, for interstitial particles and droplets during the event. The bold lines are log-normal fits to the data. (c) Estimated cloud droplet solute concentration as a function of the droplet size and dry (residue) particle size on 30 August 2010, at 23:51 UTC. The projections show droplet solute concentration as a function of interstitial particle diameter (left) and ambient particle diameter (right). The bottom projection shows the ambient particle diameter, $D_{\mathrm{d}}$, as a function of dry (residual) particle diameter, $D_{\mathrm{P}}$. The dashed lines show the limits of droplet activation for an ammonium sulfate volume fraction of 0.5 according to the Köhler theory in each projection. measured dry particle diameters into an ambient particle size distribution. The components of the DAA, such as the DMAs (dimensions, flows, transfer function) and the CPCs, have been calibrated and characterized to provide the necessary input for data evaluation, ensuring reliable results.

The data can be evaluated with automatic fitting of the charge distribution. For particle number concentration of $\mathrm{d} N / \mathrm{d} \log D_{\mathrm{p}}=12.5 \mathrm{~cm}^{-3}$ ambient particle diameters down to $0.050 \mu \mathrm{m}$ can be determined with an error of $\pm 0.005 \mu \mathrm{m}$. The fitting routine is run automatically; however, manual screening of the results is necessary. In cases of low number concentrations in particular, manual fitting is sometimes needed to identify the interstitial particle and cloud droplet distributions. The estimated uncertainties in the basic DAA parameters, i.e., the diameters of ambient and dry particles and the number concentration, are $12 \%, 6 \%$ and $<13 \%$, respectively.

The inversion algorithm presented here was developed to evaluate long-term DAA data by using more automated data processing, making it possible to evaluate larger amounts of data. The presented data are part of long-term measurements made during 2010 on Mt. Brocken, performed with a version of the DAA designed for long-term measurements, with better time resolution than the previous version of the instrument. The data show the capability of the DAA when studying the influence of aerosol properties on clouds. The three-parameter DAA data set is presented in relation to thermodynamic activation with various aspects of the cloudaerosol data set, such as the number concentration of interstitial particles and cloud droplets, the dry particle size distribution, droplet size distributions, scavenging ratios due to cloud droplet formation and size-dependent solute concentrations. Both the improved version of the DAA and the inversion algorithm will help to relate aerosol and cloud properties to facilitate investigations of cloud and fog formation.

Acknowledgements. Funding from the Swedish Research Council for Environment, Agricultural Sciences, and Spatial Planning (FORMAS); the Swedish Research Council (VR); and the Crafoord Foundation is gratefully acknowledged. A postdoctoral grant from LTH, Lund University, Sweden, to Staffan Sjogren is gratefully acknowledged. We thank Detlev Möller, Wolfgang Wieprecht, Karin Acker, Dieter Kalass and Jürgen Hofmeister at Brandenburg Technical University, Cottbus, Germany, for help and support with the field station on Mt. Brocken.

Edited by: P. Herckes

\section{References}

Albrecht, B. A.: Aerosols, cloud microphysics, and fractional cloudiness, Science, 245, 1227-1230, 1989.

Anderson, T. L., Charlson, R. J., and Covert, D. S.: Calibration of a Counterflow Virtual Impactor at Aerodynamic Diam- 
eters from 1 to $15 \mu \mathrm{m}$, Aerosol Sci. Technol., 19, 317-329, doi:10.1080/02786829308959639, 1993.

Belyaev, S. and Levin, L.: Techniques for collection of representative aerosol samples, J. Aerosol Sci., 5, 325-338, 1974.

Cederfelt, S. I., Martinsson, B. G., Svenningsson, B., Weidensohler, A., Frank, G., Hansson, H. C., Swietlicki, E., Wendish, M., Beswick, K. M., Bower, K. N., Gallagher, M. W., Pahl, S., Maser, R., and Schell, D.: Field validation of the droplet aerosol analyser, Atmos. Environ., 31, 2657-2670, 1997.

Draxler, R. and Rolph, G.: HYSPLIT (HYbrid Single-Particle Lagrangian Integrated Trajectory) Model access via NOAA ARL READY Website http://ready.arl.noaa.gov/HYSPLIT.php, NOAA Air Resources Laboratory, Silver Spring, MD, 2013.

European Environment Agency: Air quality in Europe, 2012 report, Tech. rep., European Environment Agency, 2012.

Frank, G., Martinsson, B. G., Cederfelt, S.-I., Berg, O. H., Swietlick, E., Wendisch, M., Yuskiewicz, B., Heitzenberg, J., Wiedensohler, A., Orsini, D., Stratmann, F., Lai, P., and Ricci, L.: Droplet formation and growth in polluted fogs, Contr. Atmos. Phys., 71, 65-85, 1998.

Frank, G. P., Cederfelt, S.-I., and Martinsson, B. G.: Characterisation of a unipolar charger for droplet aerosols of 0.1-20 $\mu \mathrm{m}$ in diameter, J. Aerosol Sci., 35, 117-134, 2004.

Frank, G. P., Berghof, M., Sjogren, S., and Martinsson, B.: A Droplet Aerosol Analyser (DAA) for Longterm Aerosol-Cloud Microphysics Measurements, in preparation, 2014.

Hoppel, W. A., Frick, G. M., and Fitzgerald, J.: Deducing droplet concentration and supersaturation in marine boundary layer clouds from surface aerosol measurements, J. Geophys. Res., 101, 26553-26565, 1996.

Kandler, K. and Schütz, L.: Climatology of the average watersoluble volume fraction of atmospheric aerosol, Atmos. Res., 83, 77-92, doi:10.1016/j.atmosres.2006.03.004, 2007.

Karlsson, M. N. A. and Martinsson, B. G.: Methods to measure and predict the transfer function size dependence of individual DMAs, J. Aerosol Sci., 34, 603-625, 2003.

Lawless, P. A.: Particle charging bounds, symmetry rrelation, and an analytic charging rate model for the continuum regime, $\mathrm{J}$. Aerosol Sci., 27, 191-215, 1996.

Liou, K.-N. and Ou, S.-C.: The Role of Cloud Microphysical Processes in Climate:An Assessment From a One-Dimensional Perspective, J. Geophys. Res., 94, 8599-8607, 1989.

Lohmann, U. and Feichter, J.: Global indirect aerosol effects: a review, Atmos. Chem. Phys., 5, 715-737, doi:10.5194/acp-5-7152005, 2005.

Martinsson, B. G.: Physical basis for a droplet aerosol analysing method, J. Aerosol Sci., 27, 997-1013, 1996.

Martinsson, B. G., Cederfelt, S. I., Svenningsson, B., Frank, G., Hansson, H. C., Swietlicki, E., Wiedensohler, A., Wendisch, M., Gallagher, M. W., Colvile, R. N., Beswick, K. M., Choularton, T. W., and Bower, K. N.: Experimental determination of the connection between cloud droplet size and its dry residue size, Atmos. Environ., 31, 2477-2490, 1997.

Martinsson, B. G., Frank, G. P., Cederfelt, S.-I., Swietlicki, E., Berg, O. H., Zhou, J., Bower, K. N., Bradbury, C., Birmili, W., Stratmann, F., Wendisch, M., Wiedensohler, A., and Yuskiewicz, B. A.: Droplet nucleation and growth in orographic clouds in relation to the aerosol population, Atmos. Res., 50, 289-315, 1999.
Martinsson, B. G., Frank, G., Cederfelt, S. I., Berg, O. H., Mentes, B., Papaspiropolos, G., Swietlicki, E., Zhou, J., Flynn, M., Bower, K. N., Choularton, T. W., Mäkelä, J., Virkkula, A., and $\mathrm{v}$ Dingenen, R.: Validation of very high cloud droplet number concentrations in air masses transported thousands of kilometres over the ocean, Tellus, 52, 801-814, 2000.

Martinsson, B. G., Karlsson, M. N. A., and Frank, G.: Metodology to Estimate the Transfer Function of Individual Differential Mobility Analyzers, Aerosol Sci. Technol., 35, 815-823, 2001.

Mertes, S., Lehmann, K., Nowak, A., Massling, A., and Wiedensohler, A.: Link between aerosolhygroscopic growth and droplet activation observed for hill-capped clouds at connected flow conditions during FEBUKO, Atmos. Environ., 39, 4247-4256, 2005.

Noone, K. J., Ogren, J. A., Heintzenberg, J., Charlson, R. J., and Covert, D. S.: Design and Calibration of a Counterflow Virtual Impactor for Sampling of Atmospheric Fog and Cloud Droplets, Aerosol Sci. Technol., 8, 235-244, doi:10.1080/02786828808959186, 1988.

Ogren, J. A., Heintzenberg, J., and Charlson, R. J.: In-situ sampling of clouds with a droplet to aerosol converter, Geophys. Res. Lett., 12, 121-124, doi:10.1029/GL012i003p00121, 1985.

Schwarzenboeck, A. and Heintzenberg, J.: Cut size minimization and cloud element break-up in a ground-based CVI, J. Aerosol Sci., 31, 477-489, 2000.

Sjogren, S., Frank, G. P., Berghof, M. I. A., and Martinsson, B. G.: Continuous stand-alone controllable aerosol/cloud droplet dryer for atmospheric sampling, Atmos. Meas. Tech., 6, 349357, doi:10.5194/amt-6-349-2013, 2013.

Sorensen, C. M., Gebhart, J., O'Hern, T. J., and Rader, D. J.: Optical Measurement Techniques: Fundamentals and Applications, 269-312, John Wiley \& Sons, Inc., doi:10.1002/9781118001684.ch13, 2011.

Spiegel, J. K., Zieger, P., Bukowiecki, N., Hammer, E., Weingartner, E., and Eugster, W.: Evaluating the capabilities and uncertainties of droplet measurements for the fog droplet spectrometer (FM-100), Atmos. Meas. Tech., 5, 2237-2260, doi:10.5194/amt5-2237-2012, 2012.

Stevens, B. and Feingold, G.: Untangling aerosol effects on clouds and precipitation in a buffered system, Nature, 461, 607-613, 2009.

Stolzenburg, M. R.: An ultrafine aerosol size distribution measuring system., Ph.D. thesis, University of Minnesota, 1988.

Svenningsson, B., Hansson, H.-C., Martinsson, B. G., Wiedensohler, A., Swietlicki, E., Cederfelt, S.-I., Wendisch, M., Bower, K. N., Choularton, T. W., and Colvile, R. N.: Cloud droplet nucleation scavenging in relation to the size and hygroscopic behaviour of aerosol particles, Atmos. Environ., 31, 2463-2475, 1997.

Twomey, S.: Pollution and the planetary albedo, Atmos. Environ., 8, 1251-1256, 1974.

Warner, J.: A Reduction in Rainfall Associated with Smoke from Sugar-Cane Fires - An Inadvertent Weather Modification?, J. Appl. Meteorol., 7, 247-251, 1968.

Wiedensohler, A.: An approximation of the bipolar charge distribution for particles in the submicron size range, J. Aerosol Sci., 19, 387-389, 1988. 